\title{
Emerging Themes in the Ecology and Management of North American Forests
}

\author{
Terry L. Sharik, ${ }^{1}$ William Adair, ${ }^{1}$ Fred A. Baker, ${ }^{1}$ Michael Battaglia, ${ }^{2}$ Emily J. Comfort, ${ }^{3}$ \\ Anthony W. D'Amato, ${ }^{4}$ Craig Delong, ${ }^{5}$ R. Justin DeRose, ${ }^{1}$ Mark J. Ducey, ${ }^{6}$ Mark Harmon, ${ }^{3}$ \\ Louise Levy, ${ }^{7}$ Jesse A. Logan, ${ }^{8}$ Joseph O'Brien, ${ }^{9}$ Brian J. Palik, ${ }^{10}$ Scott D. Roberts, ${ }^{11}$ Paul C. \\ Rogers, ${ }^{12}$ Douglas J. Shinneman, ${ }^{13}$ Thomas Spies, ${ }^{14}$ Sarah L. Taylor, ${ }^{15}$ Christopher Woodall, ${ }^{16}$ \\ and Andrew Youngblood ${ }^{17}$
}

\author{
${ }^{1}$ Department of Wildland Resources, Utah State University, Logan, UT 84322, USA \\ ${ }^{2}$ Rocky Mountain Research Station, USDA Forest Service, Fort Collins, CO 80526, USA \\ ${ }^{3}$ Department of Forest Ecosystems and Society, Oregon State University, Corvallis, OR 97331, USA \\ ${ }^{4}$ Department of Forest Resources, University of Minnesota, Saint. Paul, MN 55108, USA \\ ${ }^{5}$ BC Ministry of Forests and Range, Prince, George, BC, Canada V2L $3 \mathrm{H} 9$ \\ ${ }^{6}$ Department of Natural Resources and the Environment, University of New Hampshire, Durham, NH 03824, USA \\ ${ }^{7}$ Cloquet Forestry Center, University of Minnesota, Cloquet, MN 55720, USA \\ ${ }^{8}$ USDA Forest Service (retired), Box 482, Emigrant, MT 59027, USA \\ ${ }^{9}$ Center for Forest Disturbance Science, USDA Forest Service, Athens, GA 30602, USA \\ ${ }^{10}$ Northern Research Station, USDA Forest Service, Grand Rapids, MN 55744, USA \\ ${ }^{11}$ Department of Forestry, Mississippi State University, MS 39762, USA \\ ${ }^{12}$ Western Aspen Alliance, Utah State University, Logan, UT 84322, USA \\ ${ }^{13}$ U.S. Geological Survey, Forest and Rangeland Ecosystem Science Center, Boise, ID 83706, USA \\ ${ }^{14}$ Pacific Northwest Research Station, USDA Forest Service, Corvallis, OR 97730, USA \\ ${ }^{15}$ School of Life Sciences, Keele University, Keele, Staffordshire 5T5 5BG, UK \\ ${ }^{16}$ Northern Research Station, USDA Forest Service, Saint. Paul, MN 55108, USA \\ ${ }^{17}$ Pacific Northwest Research Station, USDA Forest Service, LaGrande, OR 97850, USA
}

Correspondence should be addressed to Terry L. Sharik, terry.sharik@usu.edu

Received 26 July 2009; Revised 18 November 2009; Accepted 10 December 2009

Academic Editor: Hamish Kimmins

Copyright ( 2010 Terry L. Sharik et al. This is an open access article distributed under the Creative Commons Attribution License, which permits unrestricted use, distribution, and reproduction in any medium, provided the original work is properly cited.

\begin{abstract}
The 7th North American Forest Ecology Workshop, consisting of 149 presentations in 16 oral sessions and a poster session, reflected a broad range of topical areas currently under investigation in forest ecology and management. There was an overarching emphasis on the role of disturbance, both natural and anthropogenic, in the dynamics of forest ecosystems, and the recognition that legacies from past disturbances strongly influence future trajectories. Climate was invoked as a major driver of ecosystem change. An emphasis was placed on application of research findings for predicting system responses to changing forest management initiatives. Several "needs" emerged from the discussions regarding approaches to the study of forest ecosystems, including (1) consideration of variable spatial and temporal scales, (2) long-term monitoring, (3) development of universal databases more encompassing of time and space to facilitate meta-analyses, (4) combining field studies and modeling approaches, (5) standardizing methods of measurement and assessment, (6) guarding against oversimplification or overgeneralization from limited site-specific results, (7) greater emphasis on plant-animal interactions, and (8) better alignment of needs and communication of results between researchers and managers.
\end{abstract}

\section{Introduction}

Forests are extremely complex systems that respond to an overwhelming number of biological and environmental factors, which can act singularly and in concert with each other, as exemplified by Puettmann et al. [1]. The complexity of forest systems presents an enormous challenge for forest 
researchers who try to deepen their understanding of the structure and function of these systems, and for forest managers who try to deploy practices that emulate natural processes. This paper addresses key issues in forest research and management and is divided into three sections: (1) disturbance, (2) emerging roles of forest detritus, and (3) ecological applications in the management of forest ecosystems. Disturbance emerged as a major theme from the workshop and is, thus, treated at some length and includes a subsection on ecosystem recovery to emphasize the controversy and special challenges of restoration as a management tool. Forest detritus is given a separate section as it is increasingly viewed in a broader context. The ecological applications section highlights the call for alignment between research and management needs and for better communication of results to forest managers. We conclude with future research needs regarding approaches to forest ecosystem studies. (The North American Forest Ecology Workshop biennial series began in 1997 with the objective of providing a forum for ecologists to discuss recent findings and trends in the basic and applied ecology of North American forests [2]. The 2009 workshop, held in Logan, Utah, on June 22-25, http://www.nafew2009.org/, was attended by approximately 200 delegates and featured 149 presentations in 16 oral topical sessions and a poster session. There was no specific theme for the workshop; instead, sessions were organized by researchers to explore particular aspects of forest ecology and to reflect current trends in research. A discussion was held at the end of each topical session, led by the organizers and facilitators and open to all session participants, to identify key emerging themes and areas for future research. Poster presentations were included as appropriate. This article represents a synopsis of the emerging themes, with a strong emphasis on implications for management of North American forests. An expanded version of this synopsis, together with abstracts of all workshop presentations and Power Points of a subset of workshop presentations, can be found in the Utah State University Digital Commons at http://digitalcommons.usu.edu/nafecology/.)

\section{Disturbance}

Research is needed to develop an understanding of the mechanisms that regulate how ecosystems change in response to both rapid (e.g., wildfire, wind storms) and more gradual (e.g., climate change) disturbance agents. This will improve our understanding of ecological resilience and assist forest managers in maintaining biological diversity across multiple scales. While we cannot hope to truly emulate natural disturbance in forests, we can take cues from these complex systems to achieve our end goal of ecosystem-based management.

Disturbance interactions are ubiquitous in forest ecosystems and can result in complex dynamics that affect successional trajectories, forest landscape patterns, and ecological processes at multiple spatial and temporal scales [3-5]. Consequently, understanding disturbance interactions, including predicting the magnitude and scale of future interactions, is a challenging area for future forest ecology research.
Interactions may occur among various forest disturbance agents, including insect and disease outbreaks, windthrow, timber harvest, and fire. These complex dynamics have been addressed in past research via field-based research, simulation models, and theoretical models [6]. Core research themes have included (1) investigating the ability of past disturbance events to affect future disturbance intensities and severities (2) determining how spatial legacies created by past disturbance events influence the spatial patterns, frequency, and synchrony of future disturbance events and (3) understanding the potential for synergistic interactions among disturbance agents that can dramatically alter forest composition, structure, and function through time and space. There has been an increasing focus on large landscapes and long-time periods, in part, due to technological and conceptual advances in forest landscape simulation models [7]. Insects, diseases, and fire as disturbance agents emerged as major areas of presentation and discussion, and thus are addressed below in some detail.

2.1. Insects and Diseases. Insects and fungi not only kill trees, but also cause cascading effects in ecosystems. We need a better understanding of host physiology and how it affects host defense and reproductive capabilities. Millions of trees die, but we still do not understand how. In some western forests, white pine blister rust has almost eliminated western white pine (Pinus monticola) from the canopy, resulting in conversion to Douglas fir (Pseudostuga menziesii) and true firs (Abies spp.) [8]. These replacement species are much more susceptible to bark beetles and root diseases, which have serious impacts on forest structure after about 80 years. Mountain pine beetles not only affect timber volumes and future stand composition, but can also affect water yield in quantity and timing, a key societal demand at least in western Northern American forests. Other insects and fungi are changing species composition with unknown consequences. For example, dogwood anthracnose, a canker caused by the fungus Discula destructiva, is reducing the flowering dogwood (Cornus florida) population by more than $50 \%$ over much of the host range [9], yet we know relatively little about what this means to these ecosystems of which it is a part. Franklin et al. [10] state that "...overall the patterns and causes of tree death typically are complex, and we are only beginning to appreciate the complexities." This statement rings true today as we face ecosystems challenged even further by exotic pathogens and insects, and changing climate.

A prime example of the cascading effects of insects and diseases on forest ecosystems is provided by the whitebark pine- (Pinus albicaulis-) dominated forests of western North America. These forests are facing serious decline from the combined effects of an introduced pathogen (white pine blister rust, WPBR, Cronartium ribicola) and a native bark beetle (mountain pine beetle, MPB, Dendroctonus ponderosae). Since whitebark pine is both a foundation and a keystone species [11], collapse of these forests threatens the integrity of high-elevation ecosystems across the entire distribution of whitebark pine. Both primary threats are exacerbated by climate warming, which in itself poses serious long-term consequences for whitebark pine. 
The ecological consequences of whitebark pine loss are already being expressed in altered hydrology and wildlife interactions [12]. The recent magnitude of MPB mortality in whitebark pine is a new phenomenon, and relatively little is currently known regarding the dynamics of MPB populations in these forests. The following research priorities emerged, highlighting significant gaps in our understanding of tree defense chemistry, regeneration ecology, community interactions, monitoring and assessment, host species under consideration, key refugia, and bioclimatic modeling.

(i) Tree chemistry differs between host and nonhost pine species [13]; hence, the apparent reduced effectiveness of tree chemical defenses to MPB may provide a critical key to understanding outbreak dynamics in whitebark pine.

(ii) Information on regeneration is critical for projecting future prospects and effective scenario development for areas where loss of the entire cone-bearing overstory has been observed.

(iii) The loss of cone production has far-reaching impacts on whitebark pine and community associates. Whitebark pine is almost entirely dependent on Clark's nutcracker (Nucifraga columbiana) for seed dispersal and planting. The nutcracker, however, is much more of an opportunistic species and will seek other food resources if conedensity drops below a threshold [14]. There is also mounting evidence for preferential selection of WPBR-infected trees by MPB $[15,16]$. Such community-level interactions have important implications for the future of whitebark pine.

(iv) Effective monitoring is required to establish the full extent of mortality, which has been hampered by the spatial scale and speed of the MPB outbreaks, and remoteness and ruggedness of the whitebark pine habitat. Effective assessment will require a combination of on-the-ground stand surveys, aerial mapping from fixed-wing aircraft [17, 18], and satellite image interpretation [19]. Monitoring needs to be expanded to all high-elevation 5-needle pines as limber, foxtail, and bristlecone pines (Pinus flexilus, $P$. balfourania, and $P$. aristata-longaeva) are suitable hosts for MPB.

(v) MPB populations have expanded into previously marginal whitebark pine habitat as a result of warming climate conditions $[13,20]$. However, some areas are more resistant to climatic disruption than others, and trees $<\sim 15.24 \mathrm{~cm}$ DBH are not attacked by beetles. Therefore, understory and krumholtz provide a temporal buffer for maintaining whitebark pine in some landscapes. Such potential refugia need to be identified through both on-ground surveys and/or model risk assessment.

(vi) Landscape models for risk assessment have demonstrated predictive value for identifying both at-risk and resilient landscapes. These bioclimatic models can be improved to more fully represent the relationship between weather, host tree, and outbreak potential [21].

2.2. Fire. The study of fire and fire effects primarily describes the myriad of interactions between the prefire environment, fire-severity, and postfire system characteristics and responses. Regardless of ignition, fires are driven by climatic, vegetation, and edaphic factors that may or may not interact to result in variable fire severity. In turn, fire severity affects a whole host of postfire attributes such as percent mortality, snag dynamics, fuel loading, and wildlife habitat [22]. Definitions of fire severity are usually study specific and driven by the response variable of interest, and even though a fire event affects vertical vegetation strata differently, fire severity is usually defined by its effect on overstory vegetation [23].

Mixed-severity fire regimes are defined as those that kill between $30 \%$ and $70 \%$ of the overstory [24] and have a wide geographic spread, accounting for as much as 50\% of western forest types. The definition of mixed severity is hindered by the concept of severity as it manifests itself in ways that are not part of the current classification (e.g., not just canopy but surface and soil effects). Scientists and managers need to do a more careful job of characterizing fire effects related to the concept of "severity." When used alone, the term "fire severity" has relatively little value; it must be more precisely defined to really understand the effects of fire on biodiversity and ecosystem goods and services and to foster development of more robust scientific models and effective management responses. Comparisons across fires and fire regimes must be made using the same definitions of severity; even then, ecological responses are likely to differ across species, communities, and ecosystems.

The large variety of forest types, fire behaviors, and ecological responses involved also poses a challenge to better understand mixed-severity regimes. New typologies and definitions based on fundamental factors (climate, fuel succession and moisture, topography, vegetation, productivity, and spatiotemporal dynamics) are needed to characterize the major domains of spatial and temporal variability within the mixed-severity regime. Emergent characteristics of fires and fire regimes, such as patch-size distributions, could be used as a means of distinguishing mixed-severity regime types and provide some guidance for fire management. Fire behavior and effects are driven by complex interactions of climate, fuels, topography, and vegetation [25], but little is known about how the relative importance of these factors varies among forest types and among fires within forest types. Topography often plays an important role in structuring the spatial and temporal patterns in fire behavior in many mixed-severity systems and can provide a basis for manipulating fuels to modify fire behavior. Mixed-severity regimes may create spatiotemporal vegetation dynamics that "wander" through ecological space, creating a continual series of unique landscapes. We lack understanding of this process and how landscape-level legacies of past fires and land use practices alter future landscapes. For example, the proportion of late-successional tree species has increased in many forests, increasing the probability that future disturbances will be colonized by seedlings from surviving individuals of these species. Conversely, past removal of pines and other seral dominants from mixed conifer forests has reduced the probability that future disturbance patches will be colonized by these early successional species. Management actions (e.g., thinning, prescribed fire, and planting) may be needed to alter these trajectories to achieve specific or general ecological and social outcomes. 
The mixed-severity regime has characteristics of both fuel- and climate-limited fire regimes, thereby bridging the gap between fuel-driven fires of low severity, where management actions can effectively reduce fire hazard, and climate-driven fires of high severity, where management actions to lower the risks of loss of the canopy are typically ineffective. The downside is that a mixed-severity regime does not necessarily indicate whether fuel treatments would affect fire behavior because it straddles the fuellimited and climate-limited ends of the spectrum. Climate change will affect the spatial and temporal dynamics of fire regimes, possibly increasing the proportion of high-severity patches within forests that were historically characterized by bounded ranges of low, moderate, and high fire severity. Using the historical range of variability (HRV) as a goal for management will not be realistic in many regions given climate change and the cumulative effects of past land use practices. Yet, knowledge of history can provide valuable insights for efforts to achieve desired future conditions. An alternative to HRV as guidance for managers may insure the "resilience" of forests, where resilience is defined as the capacity to sustain biological diversity and produce desired goods and services following disturbances. However, for this concept to become more useful it must be defined and metrics of desired ecological conditions and behaviors must be developed and accepted.

Miyanishi [26] attributed slow progress in the field of fire ecology to a lack of interaction between environmental biophysics and ecology research disciplines. Wildland fuels should act as a bridge between the two perspectives as understanding the impacts of fuel heterogeneity on wildland fires is critical for both predicting fire behavior and understanding fire effects. Fuel heterogeneity can be defined in many ways and at many scales and can manifest itself clearly through mosaics of burned and unburned patches, and variable fire intensity within burned areas. Heterogeneity in fuels, fire behavior, and fire effects is ubiquitous at all scales but is not well understood and has been largely ignored in the literature. Moreover, the cumulative impacts of small-scale heterogeneity can influence larger-scale spatial dynamics, resulting in unanticipated fire behavior, such as increased fire intensity at the wake of small fuel-free patches. Spatially explicit measurements are critical for deriving mechanistic explanations for spatial heterogeneity-related fire behavior, especially for understanding fuel-fire-atmospheric interactions. Heterogeneity needs to be set in context of relevant scales and dimensions and ideally follows a practical nomenclature that is simple to implement and relevant for guiding management activities. A heterogeneity metric could unify fire research over broad geographic regions and facilitate examination of similarities and differences related to geography and ecosystem variability. Novel technologies, such as LIDAR (LIght Detection And Ranging) and infrared thermography, could address some of the measurement issues. Fire effects on soil are difficult to assess because soil heterogeneity is extensive and often occurs at submeter scales, hampering landscape-scale inferences. It is critical to explore the issue of scalability to determine the level of local detail required to explain landscape-scale patterns.
Fire and fire effect studies are typically focused on the immediate postfire effects rather than the long-term, postfire response to fire activity (e.g., snag dynamics over time). This short-term focus seems to be driven by the immediate postfire reaction of the public and the availability of funding for long-term fire studies. Longer-term information with respect to specific fire events, both pre- and postfire, could provide a more complete picture of what drives the fire and subsequent fire effects and how the ecosystem responds. The long-term study approach should help increase the predictability for future fire events and lead to much-needed, improved models of fire behavior, as indicated below in the discussion of the ecological impacts of mastication fuel reduction treatments. Ultimately, the need for better definitions of fire severity and longer-term studies of fire and fire effects should help to influence funding gaps from sources such as the Joint Fire Science Program.

\subsection{Ecosystem Recovery Following Disturbance. The com-} bined influence of climate change and direct human intervention on forest ecosystems has led to a recent focus of research on the recovery of ecosystems following disturbance. The concern is that postdisturbance recovery may be hampered by a lack of species adaptations to novel stresses from disturbances foreign to the ecosystem [27]. Human disturbances in the past have severely hampered ecosystem recovery due to the magnitude, severity, and extent of the disturbance, and poor adaptation of species. A classic example is the poor adaptation of native vegetation to widespread burning by Polynesian settlers in New Zealand [28].

In the context of the systems and attributes examined, the universal conclusion that "ecosystems do recover" depends on how narrowly ecosystem properties are defined. If the definition is based on broadly defined processes, biomass, or even relatively similar stand structure and species composition, then in most cases the ecosystems studied recover to a similar condition. However, if the definition is based on the full suite of species and structure present in the preexisting "natural" condition, then this is not necessarily true. Such a rigidly defined goal for recovery is questionable, especially if the objective is to manage for diversity in forest systems, in light of our evolving understanding of landscape equilibrium in these systems $[29,30]$. The exceptions to the general rule that ecosystems do recover may include (1) the impacts of forest harvesting on dead wood and (2) multiple harvest entries that target single tree species. Significant differences in dead wood levels between younger managed stands and all ages of natural stands have been noted in several studies. Moreover, the implications of continued harvest entries, targeting only single or few tree species, for tree species loss and substantial understory changes are also a common theme in recent studies.

Recovery assumes having a target condition in mind. For this approach to be ecologically meaningful, the reference point needs to be carefully considered and elements of the target condition are critical to recovery identified. Often the assumed condition is that of old forest, but in Renard et al.'s [31] recent study of paludified boreal black spruce ecosystems, the management target was an earlier successional 
stage with higher timber volumes. It is also unreasonable to expect a young managed stand to have recovered many of the attributes present in an old forest condition; the more appropriate reference is a similar-aged naturally disturbed stand. The question of how important to ecosystem and landscape function a particular ecosystem condition is must be addressed. Human interventions designed to speed up or restore a particular target condition should be treated cautiously. Although well intentioned, these interventions may lead to undesirable consequences as evidenced by our long history of fire exclusion to maintain timber values.

Future direction in recovery research should focus on synthesizing the relatively large pool of data on recovery of multiple components of well-studied ecosystems in order to address the questions stated above. New research should address what valued ecological services the ecosystem provides and at what stage during recovery it provides them, and how ecosystem recovery is linked to maintaining of critical ecosystem processes. In order to maintain ecosystem services and processes is it important that ecosystems be in different stages of recovery across time and space. Future ecosystem recovery studies should also include a wildlife component so that the recovery of stand structure and composition can be linked to habitat recovery and wildlife use. With the rapid advances in new statistical and modeling techniques, collaboration between ecologists and mathematicians will provide some useful insights in this area of ecological research.

2.4. Future Directions for Disturbance Research. Key areas for future research in forest disturbance interactions include (1) incorporating the influence of climatic variability and assessing the likely influence of global climate change on disturbance interactions and their effects (2) assessing the influence of disturbance interactions on key ecosystem processes and components, such as carbon dynamics and forest biodiversity (3) addressing the role of socioeconomic and political influences on disturbance interactions and their effects, such as diverse management histories among different land owners across regional landscapes, (4) addressing disturbance dynamics at appropriate scales, including determination of scale-sensitive detection thresholds for specific disturbance interactions and their effects, (5) considering the degree to which forest management can (or should) emulate more complex disturbance interactions, and (6) using iterative approaches to better coordinate research (e.g., modeling) and forest management such that research informs possible new management directions and the results of management inform and guide future research. Finally, to help accomplish these objectives, better data are often needed to inform both management and research, not only via acquisition of better empirical data from field research and long-term monitoring, but also by developing better access to, or compilations of, existing datasets that encompass large forested landscapes and long-time periods.

\section{Emerging Roles of Forest Detritus}

The role that dead wood plays in forest ecosystems was first comprehensively detailed nearly three decades ago [32].
Dead wood was initially highlighted as a vital attribute of old growth forests, providing habitat for fauna and niches for plant species regeneration [33]. A slightly divergent track of dead wood research has been that of fire and fuel sciences. Instead of focusing on the role that dead wood plays in forest ecosystem processes, fire research has sought to refine estimates and management of fuel loadings [34]. With the onset of the 21st century, dead wood resources have now been framed as a vital carbon stock [35] in terms of both sequestration and emission (i.e., wildfires)—all within a changing climate [36]. Perhaps due to the diverse array of research directions that have beset dead wood investigations, there has been no focal point for assimilating decades of wide-ranging dead wood study results. To wit, the contribution of standing, down, and buried dead wood to forest ecosystem processes and carbon fluxes is often ignored or underappreciated. Dead wood may be a controlling factor in many forest ecosystem processes such as regeneration establishment, soil carbon efflux, and soil stability. Ultimately, the entire carbon cycle of forest stands may be controlled by dead wood following disturbances (e.g., seedling establishment and disturbance recovery), especially in higher-latitude forests (e.g., boreal). Dead wood carbon stocks may not be as ephemeral as assumed, since buried dead wood in boreal systems can remain for 200-300 years. The contemporary emphasis on utilization of residual dead wood biomass following harvest operations has increased pressure on dead wood resources, possibly altering dead wood ecosystem processes beyond our current understanding. Exacerbating the knowledge gaps of dead wood biomass utilization is that the drivers of dead wood decay processes across the diverse forest ecosystems of North America are vastly unknown. Dead wood simulation models typically do not include climatic variables and are, thus, not sensitive to climate change effects on dead wood accumulation/decay processes [37]. A whole array of forest carbon policy and management decisions that have been predicated on dead wood simulation models may be in error. Even empirical dead wood surveys may not have adequate sample intensities to statistically detect substantial changes in dead wood carbon stocks across large scales. Overall, expanded, systematic/long-term research in the areas of dead wood decay processes is suggested. Furthermore, a joining of forest inventories with dead wood simulation models is suggested to benefit refined forest ecosystem carbon stock estimation. Across North America dead wood resources systematically impact forest ecosystems, and thus are deserving systematic study.

\section{Ecological Applications in the Management of Forest Ecosystems}

4.1. Alternative Silvicultural Approaches. The use of largescale alternative silvicultural approaches for achieving multiple objectives of forest management has become increasingly widespread throughout North America [38-40]. Variable retention harvests, fuel reduction treatments, and other 
restoration practices have been utilized and studied in systems from the oak-hickory forests of the southern US to the temperate rainforests of the Pacific Northwest and the boreal mixedwoods of Canada. Because forest restoration generally focuses on restoring structure characteristic of older forests, these practices are necessarily long-term endeavors.

There are several critical issues affecting the use of these ecosystem-management approaches. The continuity of research to evaluate the efficacy of treatments over greater spatial and temporal scales is important to determine best practices, but difficult to plan and implement over time. As a result, regeneration responses to these treatments abound $[41,42]$, but longer-term responses are less well documented. In some cases, this is simply due to the lack of time that has elapsed since initiation of these studies, but often it is due to the difficulty in sustaining long-term funding for such studies. Additionally, there are many tradeoffs involved in these restoration approaches from both a forest resource management perspective and a sociological perspective. Finally, the objectives of these studies are generally very broad (increase structural diversity, restore to historic range of variability) and not precisely defined (how do you measure "greater structural diversity" and will it achieve the ultimate management goals?).

Future solutions to many of these issues may include reviving older studies that have "dropped off the radar" but which may provide the long-term data lacking in more recent studies. Another potentially fruitful approach would be to combine field results with modeling approaches. This would allow longer-term projections to see whether treatments are meeting long-term goals and would also allow continual recalibration of the models with the best available empirical data.

4.2. Long-Term Studies in Experimental Forests. Across North America, a network of experimental forests provides an incredible wealth of records and knowledge of environmental change in natural and managed forest ecosystems. The United States Department of Agriculture Forest Service celebrated the 100th anniversary of its network of 81 experimental forests in 2008. National Research Forests administered by the Canadian Forest Service have similar mandates and legacies. Experimental forests provide places for long-term science and management studies in all the major forest vegetation types in North America. They are living laboratories where discoveries are made and research results are demonstrated for cooperators and stakeholders [43]. Experimental forests provide valuable opportunities to observe changes in forest composition and structure over extended periods, yet many experimental forests are undergoing shifts in research missions as societal demands and needs shift. The following represent some of the key aspects of experimental forests with respect to their establishment, shifting missions, and current emphases.

Many experimental forests were established during or after other dominant land uses had occurred. For example, the Bent Creek (North Carolina), Coweeta (North Carolina), Crossett (Arkansas), Cutfoot Sioux (Minnesota), Fort Valley (Arizona), and Santee (South Carolina) experimental forests still contain legacies of landscape-scale tree harvesting and railroad logging, fire suppression, livestock grazing, or diversion of water for agriculture. Thus, these sites provide a rich history of past disturbance events and both natural restoration processes and diverse restoration treatments. Because many experimental forests were previously logged during more exploitive periods, a common early research priority was establishment of stands and forests that best represented natural stand structures, demonstrated by early work at Cutfoot Sioux, Santee, Bent Creek, Crossett, and at the Canadian Petawawa Research Forest in Ontario. This work is proven valuable today as federal, state, and provincial forest management strategies have shifted to incorporate a greater emphasis on restoration of structure and processes.

Experimental forests frequently were sites for early research designed to evaluate methods of harvesting and regeneration techniques that aided the timber management industry, including Bent Creek, Crossett, Petawawa, Fort Valley, and Pringle Falls (Oregon). This support, almost universal across the network, now rarely exists. Moreover, experimental forests often provide opportunities to address new questions with existing databases, such as using nearly a century of recorded vegetation dynamics at Coweeta or Fort Valley to evaluate the effects of introduced disease, introduced insects, and climate change or nearly a century of recorded vegetation dynamics under known management regimes at Crossett, Cutfoot Sioux, Petawawa, Fort Valley, and Pringle Falls to evaluate opportunities for biomass conversion and carbon sequestration.

Current long-term research at various experimental forests may provide unique opportunities for linking efforts across similar sites to calibrate and validate landscapeand regional-scale models supporting policy decisions. As a first step, workshop attendees recommend that a catalog of long-term datasets should be developed based on the prototype designed by the Canadian Forest Service in British Columbia.

4.3. Ecological Classification Systems. Ecological classification systems have existed in North America for several decades. However, the importance of these systems in guiding the conservation and management of forest ecosystems has increased substantially within recent years. In particular, policy mandates for the use of ecosystem-based approaches for forest management, driven in large part by forestland certification programs [44], have created a need for the development and verification of systems that classify terrestrial vegetation into ecologically and administratively meaningful units on the landscape. Nationwide efforts, such as the development and refinement of the map of ecological subregions by the US Forest Service, are facilitating efforts to develop forest-wide plans for National Forests and other federal lands. Likewise, regional efforts, such as those in the central Rocky Mountains, Lake States, and British Columbia, are providing locally calibrated classification systems $[45,46]$ that offer a framework for addressing management and conservation challenges within environmentally complex landscapes. 
Collectively, these classification approaches provide an invaluable platform for communicating information about site-level ecological concepts and processes across management and conservation agencies and research institutions. As such, these classification systems are a valuable tool for seeking commonalities across scientific investigations examining issues such as the decline of aspen in the western United States, as well as in evaluating the response of managed ecosystems to novel ecologically based silvicultural treatments. Ultimately, the relevance and utility of these approaches and tools hinge on outreach and education programs that translate the concepts of ecological classification systems to scales relevant to foresters, wildlife biologists, planners, and scientists. Without these efforts, the ability of these tools to facilitate the development of ecosystem management approaches is limited.

4.4. Stand Density Indices. The ideas, applications, and new developments for measuring stand density were examined, using Reineke's [47] original work on Stand Density Index (SDI) as a touchstone. While some practitioners have eschewed SDI, preferring basal area for its simplicity of measurement [48], others have criticized SDI and related approaches for a lack of ecological complexity [49]. Still, Zeide [50] calls SDI the best available stand density metric, and its fascination in silvicultural and ecological research has been enduring.

From boreal mixedwoods in the north to tree hammocks in south Florida and from Oregon in the west to New England in the east, Reineke's ideas continue to provide raw material for a variety of exciting work that attempts to extend the application of his original work in monocultures to mixed-species stands and landscapes. A challenge with SDI is that while it may provide a good measure of stand density within stands of a particular species, between species or in mixed species stands, it may be less appropriate and other measures may perform better. Another recent area of fruitful investigation has been the connection between stand density and dead wood pools at a national scale, focused on interpreting stand density ecologically over a broad range of species composition and dead wood decomposition rates [51].

There is a growing tendency to use density measures related to Reineke's SDI for a range of silvicultural and ecological objectives, far beyond the traditional timber management goals anticipated by Reineke [47] and emphasized in recent reviews (e.g., [50]). Moreover, difficulty of adapting simple density measures to the complexity of mixed species stands continues to challenge researchers with a strong interest in the application of SDI in forest management. Must we capture the full complexity of species interactions to provide a density measure that is informative, or will some simpler approach suffice? And what, given the range of management and scientific objectives, would constitute a sufficient approach? Finally, there is a critical need for testing and comparing different density measures. Evaluating and comparing these measures by treating them as competing hypotheses about ecological behavior remains both valuable and uncommon.
4.5. Mastication Fuel Reduction Treatments. Mastication treatments involve shredding, chopping, or chipping small trees and/or shrubs into small chunks and leaving the material on site as a way to reduce crown-fire risk. Managers and the public are interested in understanding the impacts of the addition of this woody material on forest ecosystems so that they can evaluate the ecological impacts of this novel management technique. Mastication substantially decreases tree density and increases the amount of surface fuel loadings with the majority of deposited fuels $<2.54 \mathrm{~cm}[52-54]$. The shifts in the fuelbed composition from a needle-dominated to a woody-dominated fuelbed have been found to impact vegetation recovery and alter soil nutrients and abiotic conditions. Herbaceous plant cover has been observed to increase after mastication treatments in pinyon pine-juniper and ponderosa pine ecosystems, but not in mixed conifer or lodgepole pine ecosystems [55]. Presence of exotic species increases in all masticated areas $[55,56]$. The addition of mulch to the forest floor alters soil moisture and temperature by moderating the fluctuation in temperatures, maintaining cooler temperatures in Summer and warmer temperatures in Winter and retaining moisture [57]. Although soil moisture and temperature are altered, impacts to nitrogen availability vary among and within the ecosystems under consideration. Some pinyon-juniper sites show no change in nitrogen mineralization, while others show an increase in ammonium $[57,58]$. Nitrogen has been shown to decline with increased mulch depth for the pinyon-juniper and lodgepole pine ecosystems, but not for the ponderosa pine ecosystem [57]. The addition of mulch to the forest floor does not appear to alter the $\mathrm{C}: \mathrm{N}$ ratio in the pinyon-juniper ecosystem. However, the loss of AMF fungi richness after 2.5 years in the pinyon-juniper ecosystem has been noted [56].

Because of the infancy of this novel management treatment, the ecological impacts are still unclear. While there are some general trends in recent investigations, future research is needed. It is clear that ecosystems differ in their initial and short-term ( 2 to 4 years post treatment) response to the addition of woody material. However, it is unclear whether changes within a site among years are a result of climatic differences or ecosystem recovery. This highlights the need for continued longer-term studies of these treatments. Chronosequence studies of mulch sites in ecosystems along a latitudinal gradient are needed to examine changes in $\mathrm{C}: \mathrm{N}$ ratio of the woody material, soil microbial communities, decomposition rates, soil nitrogen, tree regeneration, and tree growth. In addition, studies that assess the long-term impact to herbaceous plant community composition and production are still needed. Longer-term studies are also needed to determine the longevity of these treatments to reduce crown-fire risk. The impact that microand macro-vertebrates are having on vegetation recovery and nutrient dynamics in these ecosystems is still unknown. The lack of fire behavior fuel models to describe these new fuel beds hinders our ability to determine the fire behavior and effects on these treatment areas [53, 59]. More research in the development of new fuel models to estimate fuel loads and their physical properties is still needed for each of the ecosystems. Finally, working with managers so that they leave 
reference controls within the treatment area is important, so we can assess the impacts of the treatments and provide feedback for adaptive management.

4.6. Aspen Management. Anecdotal evidence from field visits and conversations with land managers suggests that practitioners involved in the management of quaking aspen (Populus tremuloides) are operating with assumptions based on 20-30-year-old science. Much of Canadian national and provincial forest management is strongly influenced by commercial timber harvesting, whereas U.S. policy and practice has, in recent years, been dominated by public involvement favoring conservation of species, recreational interests, and aesthetics. Land management geared toward conservation is more prominent in areas where aspenand forest harvesting generally-is less commercially viable for various reasons (i.e., growth habits, ease of access, and political/economic climates). In the U.S. Lake States and boreal Canada, aspen is considered a prime commercial tree species, whereas in the mountain west of the U.S. this is not the case.

Despite these divergent policy agendas between these two countries, a few prominent themes emerge. It is generally agreed that there is not a single "aspen forest," but many functional aspen types. Thus, it would benefit managers and researchers to focus on the specifics of how these types differ ecologically and how they might be managed more effectively with that base of knowledge. Recent investigations of the key indicators of aspen health (i.e., sustainability) suggest that pooling findings from various ecosystems for application in monitoring would advance the field. For example, recent Canadian research [60] clearly points to the high value of examining root system status as an indicator of aspen health. In the US, focus on aboveground regeneration "health" has resulted in its emergence as a prominent indicator in stable aspen forests (e.g., [61].) There is also a need to improve monitoring via standardization of methods and terminology. Often researchers show conflicting results in functionally similar aspen communities, and thus send mixed messages to earnest land managers (e.g., contrast [62] with [63]). Upon further scrutiny, differing conclusions are rooted in dissimilar definitions or approaches. Finally, it is worth noting that policy makers throughout aspen's range either have not understood or are reluctant to act on ecological pleas for the benefits of large-scale disturbance (primarily fire) to aspen systems. One benefit that has been widely discussed is the need to "overwhelm" ungulate herbivory of suckers by affecting much bigger areas of the landscape with prescribed natural fire.

Major research topics in need of further investigation include genetics and phytochemistry, management applications, wildlife habitat, monitoring methods and range of natural variability, connecting ecology to policy, effects of climate warming/drought (i.e., Sudden Aspen Decline in U.S. Southwest and aspen expansion in Canadian Rockies), incorporating social science (e.g., clarify aspen benefits to society), and aspen's ecological relation to conifer beetle kill. Research has already begun on the first four topics, while the last four topics have seen little or no emphasis to date.
Each of these topics is deserving priority status directed, ultimately, toward answering our respective constituency's concerns about aspen ecosystem status and health.

\section{Future Directions}

As a precursor, it should be noted that the voluntary nature of participation in this workshop understandably resulted in the omission of several current topics of keen interest to forest researchers and managers, including climate change, carbon dynamics, biodiversity, invasive species, and biofuels. Hopefully, these and other omissions will encourage others to join the expanding ranks of those who participate in these workshops.

Several "needs" did emerge from the workshop regarding approaches to the study of forest ecosystems, including (1) consideration of variable spatial and temporal scales, (2) long-term monitoring, (3) development of universal databases more encompassing of time and space to facilitate metaanalyses, (4) combining field studies and modeling approaches, (5) standardizing methods of measurement and assessment, (6) guarding against oversimplification or overgeneralization from limited site-specific results, (7) greater emphasis on plant-animal interactions, and (8) better alignment of research with management needs and better translation of results for managers. An elaboration of several of these needs appears above in various sections of this paper.

Of special concern is the fact that conventional studies of limited duration and scale have proven inadequate for examining ecological processes that depend on many complex interactions and function over longer time scales. This observation suggests that a formal discussion concerning the pressing need for coordination among studies should be initiated, with an initial emphasis on a synthesis of current studies of ecosystem processes across geographic regions and ecological circumstances. As a first step, these studies should be gathered together into an international catalog and database, perhaps using the Ecological Society of America (ESA) and U.S. Federal Geographic Data Committee's (FGDC) National Vegetation Classification (NVC) as a model, together with the Long-Term Ecological (LTER) and National Ecological Observatory (NEON) Networkssponsored by the U.S. National Science Foundation. A comprehensive metaanalysis of these studies could then be used to identify the most pressing unanswered questions and to set priorities for establishing a more extensive network of long-term studies that encompasses the full range of natural variability and utilizes standardized methods of measurement and assessment based on a combination of field studies and modeling efforts.

An example of research on forest ecosystems that could benefit from better alignment and communication with managers is that on gap dynamics. To date research has often focused on specific conditions within gaps, with little thought for the legacy of dead trees remaining in these gaps and how they affect forest ecosystems. Silvicultural systems that attempt to approximate gap formation typically do so by removing the trees from the system, thereby losing 
an important element of natural gap dynamics. This treecentric focus on the living component is a legacy of past forest management practices for timber-driven values. Dead trees do not disappear rapidly from the system [64]. Snags can impact regeneration by occupying canopy space and reducing ground light levels and can influence the survival of neighboring live trees [65]. These snags also provide habitat for a variety of organisms [66] as do fallen logs [67]. In the current zeitgeist of ecological management, a more holistic approach needs to be taken, not only focusing on altered conditions (composition) created by disturbance, but also placing more emphasis on the role of disturbance (process) in modifying resources. Only then can we achieve our ultimate goal of ecosystem-based management.

\section{References}

[1] K. J. Puettmann, K. D. Coates, and C. Messier, A Critique of Silviculture: Managing for Complexity, Island Press, Washington, DC, USA, 2009.

[2] T. L. Sharik and J. E. Cook, "Nafew 1997 history and overview: introduction," Forest Ecology and Management, vol. 114, no. 23, p. 169, 1999.

[3] A. E. Hessl and L. J. Graumlich, "Interactive effects of human activities, herbivory and fire on quaking aspen (Populus tremuloides) age structures in western Wyoming," Journal of Biogeography, vol. 29, no. 7, pp. 889-902, 2002.

[4] E. Howe and W. L. Baker, "Landscape heterogeneity and disturbance interactions in a subalpine watershed in Northern Colorado, USA," Annals of the Association of American Geographers, vol. 93, no. 4, pp. 797-813, 2003.

[5] C. Bigler, D. Kulakowski, and T. T. Veblen, "Multiple disturbance interactions and drought influence fire severity in rocky mountain subalpine forests," Ecology, vol. 86, no. 11, pp. 30183029, 2005.

[6] M. G. Turner, "Landscape ecology: what is the state of the science?" Annual Review of Ecology, Evolution, and Systematics, vol. 36, pp. 319-344, 2005.

[7] R. M. Scheller and D. J. Mladenoff, "An ecological classification of forest landscape simulation models: tools and strategies for understanding broad-scale forested ecosystems," Landscape Ecology, vol. 22, no. 4, pp. 491-505, 2007.

[8] J. W. Byler and S. K. Hagle, "Succession functions of pathogens and insects," FHP Report 00-09, p. 37, USDA Forest Service, State and Private Forestry, Forest Health Protection Northern Region, 2000.

[9] C. M. Oswalt, "Evidence of significant declines in Cornus florida L. populations in the Appalachian ecoregion," International Journal of Forestry Research, In press.

[10] J. F. Franklin, H. H. Shugart, and M. E. Harmon, "Tree death as an ecological process," Bioscience, vol. 37, pp. 550-556, 1987.

[11] D. Tomback, "Whitebark pine as a foundation and keystone species: functional roles and community interactions," in Proceedings of the 7th North American Forest Ecology Workshop, Logan, Utah, USA, June 2009, Whitebark Session, Paper no. 1, http://digitalcommons.usu.edu/ nafecology/sessions/whitebark/1/.

[12] L. Willcox, "The bear facts: implications of whitebark pine loss for Yellowstone grizzlies," in Proceedings of the 7th North American Forest Ecology Workshop, Logan, Utah, USA, June 2009, Whitebark Session, Paper no. 12, http:// digitalcommons.usu.edu/nafecology/sessions/whitebark/12/.
[13] B. Bentz, G. Schen, C. Boone, and K. Raffa, "Mountain pine beetle outbreak dynamics in high elevation forests," in Proceedings of the 7th North American Forest Ecology Workshop, Logan, Utah, USA, June 2009, Whitebark Session, Paper no. 3, http:/digitalcommons.usu.edu/nafecology/sessions/whitewhitebark/3/.

[14] S. T. Mckinney, C. E. Fiedler, and D. F. Tomback, "Invasive pathogen threatens bird-pine mutualism: implications for sustaining a high-elevation ecosystem," Ecological Applications, vol. 19, no. 3, pp. 597-607, 2009.

[15] N. K. Bockino, Interactions of white pine blister rust, host species, and mountain pine beetle in whitebark pine ecosystems in the greater yellowstone, M.S. thesis, University of Wyoming, Wyoming, Laramie, 2008.

[16] D. L. Six and J. Adams, "White pine blister rust severity and selection of individual whitebark pine by the mountain pine beetle (Coleoptera: Curculionidae, Scolytinae)," Journal of Entomological Science, vol. 42, no. 3, pp. 345-353, 2007.

[17] W. W. Mcfarlane, B. Gordon, J. A. Logan, and L. Willcox, "Landscape assessment and monitoring of mountain pine beetle mortality in Greater Yellowstone Ecosystem whitebark pine," in Proceedings of the 7th North American Forest Ecology Workshop, Logan, Utah, USA, June 2009, Whitebark Session, Paper no. 4, http://digitalcommons.usu.edu/nafecology/sessions/whitebark/4/.

[18] J. A. Logan, W. W. Macfarlane, and L. Willcox, "Effective monitoring as a basis for adaptive management: a case history of mountain pine beetle in Greater Yellowstone Ecosystem whitebark pine," iForest, vol. 2, pp. 19-22, 2009, http://www.sisef.it/iforest/show.php?id=477.

[19] J. A. Hicke and J. A. Logan, "Mapping whitebark pine mortality caused by a mountain pine beetle outbreak with high spatial resolution satellite imagery," International Journal of Remote Sensing, vol. 30, no. 17, pp. 4427-4441, 2009.

[20] J. A. Logan and J. A. Powell, "Ghost forests, global warming, and the mountain pine beetle," American Entomologist, vol. 47, pp. 160-173, 2001.

[21] J. Régnière, B. J. Bentz, and J. A. Powell, "An individual based model of mountain pine beetle responses to climate and host resistance," in Proceedings of the 7th North American Forest Ecology Workshop, Logan, Utah, USA, June 2009, Whitebark Session, Paper no. 9, http://digitalcommons.usu.edu/nafecology/sessions/whitebark/9/.

[22] T. B. Jain, W. A. Gould, R. T. Graham, D. S. Pilliod, L. B. Lentile, and G. Gonzalez, "A soil burn severity index for understanding soil-fire relations in tropical forests," Ambio, vol. 37, no. 7-8, pp. 563-568, 2008.

[23] T. B. Jain and R. T. Graham, "The relation between tree burn severity and forest structure in the Rocky Mountains," type Conference Paper, PSW-GTR-203, USDA Forest Service, 2005, p. 213-250.

[24] P. F. Hessburg, J. K. Agee, and J. F. Franklin, "Dry forests and wildland fires of the inland Northwest USA: contrasting the landscape ecology of the pre-settlement and modern eras," Forest Ecology and Management, vol. 211, no. 1-2, pp. 117-139, 2005.

[25] T. Schoennagel, T. T. Veblen, and W. H. Romme, "The interaction of fire, fuels, and climate across Rocky Mountain forests," BioScience, vol. 54, no. 7, pp. 661-676, 2004.

[26] K. Miyanishi, "Towards a sounder fire ecology," Frontiers in Ecology and the Environment, vol. 1, pp. 275-276, 2003.

[27] J. R. Kelly and M. A. Harwell, "Indicators of ecosystem recovery," Environmental Management, vol. 14, no. 5, pp. 527$545,1990$. 
[28] M. S. McGlone, "The Polynesian settlement of New Zealand in relation to environmental and biotic changes," The New Zealand Journal of Ecology, vol. 12, pp. 115-129, 1989.

[29] M. G. Turner, W. H. Romme, R. H. Gardner, R. V. O’Neill, and T. K. Kratz, "A revised concept of landscape equilibrium: disturbance and stability on scaled landscapes," Landscape Ecology, vol. 8, no. 3, pp. 213-227, 1993.

[30] J. F. Johnstone and F. S. Chapin, "Non-equilibrium succession dynamics indicate continued northern migration of lodgepole pine," Global Change Biology, vol. 9, no. 10, pp. 1401-1409, 2003.

[31] S. Renard, S. Gauthier, N. Fenton, and Y. Bergeron, "Assessment of prescribed burning effects in paludified black spruce forests in Ontario's Clay Belt Region," in Proceedings of the 7th North American Forest Ecology Workshop, , Ed., Logan, Utah, USA, June 2009, Ecosystem Recovery Following Disturbance Session, Paper 4, http://digitalcommons.usu.edu/ nafecology/sessions/recovery/4/.

[32] M. E. Harmon, J. F. Franklin, and F. J. Swanson, "Ecology of coarse woody debris in temperate ecosystems," Advances in Ecological Research, vol. 15, pp. 133-302, 1986.

[33] C. Maser, R. G. Anderson, K. Cromack Jr., J. T. Williams, and R. E. Martin, "Dead and down woody material," in Wildlife Habitats in Managed Forests: The Blue Mountains of Oregon and Washington Ag. Handbook, J. W. Thomas, Ed., vol. 553, pp. 78-95, USDA, Washington, DC, USA, 1979.

[34] M. G. Rollins, R. E. Keane, and R. A. Parsons, "Mapping fuels and fire regimes using remote sensing, ecosystem simulation, and gradient modeling," Ecological Applications, vol. 14, no. 1, pp. 75-95, 2004.

[35] C. W. Woodall, L. S. Heath, and J. E. Smith, "National inventories of down and dead woody material forest carbon stocks in the United States: Challenges and opportunities," Forest Ecology and Management, vol. 256, no. 3, pp. 221-228, 2008.

[36] C. W. Woodall and G. C. Liknes, "Climatic regions as an indicator of forest coarse and fine woody debris carbon stocks in the United States," Carbon Balance and Management, vol. 3, p. 5,2008 .

[37] J. E. Smith, L. S. Heath, K. E. Skog, and R. A. Birdsey, "Methods for calculating forest ecosystem and harvested carbon with standard estimates for forest types of the United States," Tech. Rep. NE-343, US Department of Agriculture, Forest Service, Northeastern Research Station, Newtown Square, Pa, USA, 2006.

[38] J. F. Franklin, T. A. Spies, R. V. Pelt, et al., "Disturbances and structural development of natural forest ecosystems with silvicultural implications, using Douglas-fir forests as an example," Forest Ecology and Management, vol. 155, no. 1-3, pp. 399-423, 2002.

[39] S. E. Reutebuch, C. A. Harrington, D. D. Marshall, and L. C. Brodie, "Use of large-scale silvicultural studies to evaluate management options in Pacific Northwest forests of the United States," Forest Snow and Landscape Research, vol. 78, no. 1-2, pp. 191-208, 2004.

[40] J. Bauhus, K. Puettmann, and C. Messier, "Silviculture for oldgrowth attributes," Forest Ecology and Management, vol. 258, no. 4, pp. 525-537, 2009.

[41] K. B. Aubry, C. B. Halpern, and C. E. Peterson, "Variableretention harvests in the Pacific Northwest: a review of shortterm findings from the DEMO study," Forest Ecology and Management, vol. 258, no. 4, pp. 398-408, 2009.
[42] S. E. Macdonald and T. E. Fenniak, "Understory plant communities of boreal mixedwood forests in western Canada: Natural patterns and response to variable-retention harvesting," Forest Ecology and Management, vol. 242, no. 1, pp. 34-48, 2007.

[43] M. B. Adams, L. Loughry, and L. Plaugher, "Experimental forests and ranges of the USDA Forest Service," Tech. Rep. NE-321, p. 178, US Department of Agriculture, Forest Service, Northeastern Research Station, Newton Square, Pa, USA, 2003.

[44] N. R. Brown, R. F. Noss, D. D. Diamond, and M. N. Myers, "Conversation biology and forest certification: working together toward ecological sustainability," Journal of Forestry, vol. 99, no. 8, pp. 18-25, 2001.

[45] R. N. Green and K. Klinka, A Field Guide to Site Identification and Interpretation for the Vancouver Forest Region, vol. 28 of Land Management Handbook, British Columbia Ministry of Forests, Victoria, BC, USA, 1994.

[46] Minnesota Department of Natural Resources (MN DNR), Field Guide to the Native Plant Communities of Minnesota: The Laurentian Mixed Forest Province, Minnesota Department of Natural Resources, St. Paul, Minn, USA, 2005.

[47] L. H. Reineke, "Perfecting a stand-density index for even-aged forests," Journal of Agricultural Research, vol. 46, no. 7, pp. 627-638, 1933.

[48] C. A. Bickford, F. S. Baker, and F. G. Wilson, "Stocking, normality, and measurement of stand density," Journal of Forestry, vol. 55, no. 2, pp. 99-104, 1957.

[49] J. H. Reynolds and E. D. Ford, "Improving competition representation in theoretical models of self-thinning: a critical review," Journal of Ecology, vol. 93, no. 2, pp. 362-372, 2005.

[50] B. Zeide, "How to measure stand density," Trees, vol. 19, no. 1, pp. 1-14, 2005.

[51] C. W. Woodall and J. A. Westfall, "Relationships between the stocking levels of live trees and dead tree attributes in forests of the United States," Forest Ecology and Management, vol. 258, no. 11, pp. 2602-2608, 2009.

[52] D. W. Huffman, P. Z. Fulé, J. E. Crouse, and K. M. Pearson, "A comparison of fire hazard mitigation alternatives in pinyon-juniper woodlands of Arizona," Forest Ecology and Management, vol. 257, no. 2, pp. 628-635, 2009.

[53] J. M. Kane, J. M. Varner, and E. E. Knapp, "Novel fuelbed characteristics associated with mechanical mastication treatments in northern California and south-western Oregon, USA," International Journal of Wildland Fire, vol. 18, no. 6, pp. 686-697, 2009.

[54] M. A. Battaglia, M. E. Rocca, C. R. Rhoades, and M. G. Ryan, "Surface fuel loadings and potential crown fire behavior within mulching treatments in Colorado coniferous forests," submitted to Forest Ecology and Management.

[55] M. E. Rocca, M. Battaglia, C. Rhoades, and M. G. Ryan, "The effects of mulching treatments on the forest herbaceous layer of Colorado coniferous forests," in Proceedings of the 7th North American Forest Ecology Workshop, Logan, Utah, USA, June 2009, Mastication Session, Paper 7, http://digitalcommons.usu.edu/nafecology/sessions/mastication/7/.

[56] S. M. Owen, C. H. Sieg, C. A. Gehring, and M. A. Bowker, "Above- and belowground responses to tree thinning depend on the treatment of tree debris," Forest Ecology and Management, vol. 259, no. 1, pp. 71-80, 2009.

[57] C. Rhoades, M. Battaglia, M. G. Ryan, and M. E. Rocca, "Woody mulch effects on soil nitrogen availability in mechanical fuel reduction treatments," in Proceedings of the 7th North American Forest Ecology Workshop, 
Logan, Utah, USA, June 2009, Mastication Session, Paper 6, http://digitalcommons.usu.edu/nafecology/sessions/mastiication $/ 6 /$.

[58] S. Overby and G. Gottfried, "Does mastication residue alter soil nitrogen dynamics in woodlands of Southwest Colorado?" in Proceedings of the 7th North American Forest Ecology Workshop, Logan, Utah, USA, June 2009, Mastication Session, Paper 3, . http://digitalcommons.usu.edu/nafecology/ sessions/mastication/3/.

[59] J. S. Glitzenstein, D. R. Streng, G. L. Achtemeier, L. P. Naeher, and D. D. Wade, "Fuels and fire behavior in chipped and unchipped plots: Implications for land management near the wildland/urban interface," Forest Ecology and Management, vol. 236, no. 1, pp. 18-29, 2006.

[60] T. L. Mundell, S. M. Landhäusser, and V. J. Lieffers, "Root carbohydrates and aspen regeneration in relation to season of harvest and machine traffic," Forest Ecology and Management, vol. 255, no. 1, pp. 68-74, 2008.

[61] P. C. Rogers, A. J. Leffler, and R. J. Ryel, "Landscape assessment of a stable aspen community in southern Utah, USA," Forest Ecology and Management, vol. 259, no. 3, pp. 487-495, 2010.

[62] B. P. Kurzel, T. T. Veblen, and D. Kulakowski, "A typology of stand structure and dynamics of Quaking aspen in northwestern Colorado," Forest Ecology and Management, vol. 252, no. 1-3, pp. 176-190, 2007.

[63] J. J. Worrall, L. Egeland, T. Eager, et al., "Rapid mortality of Populus tremuloides in southwestern Colorado, USA," Forest Ecology and Management, vol. 255, no. 3-4, pp. 686-696, 2008.

[64] E. Jones and L. D. Daniels, "Decay dynamics of coarsewood habitat in old-growth spruce and pine stands in the Rocky Mountain Foothills," in Proceedings of the 7th North American Forest Ecology Workshop, p. 31, June 2009.

[65] S. L. Taylor and D. A. MacLean, "Spatiotemporal patterns of mortality in declining balsam fir and spruce stands," Forest Ecology and Management, vol. 253, no. 1-3, pp. 188-201, 2007.

[66] S. C. DeLong, G. D. Sutherland, L. D. Daniels, B. H. Heemskerk, and K. O. Storaunet, "Temporal dynamics of snags and development of snag habitats in wet spruce-fir stands in east-central British Columbia," Forest Ecology and Management, vol. 255, no. 10, pp. 3613-3620, 2008.

[67] M. E. Harmon, J. F. Franklin, F. J. Swanson, et al., "Ecology of coarse woody debris in temperate ecosystems," Advances in Ecological Research, vol. 15, pp. 133-302, 1986. 

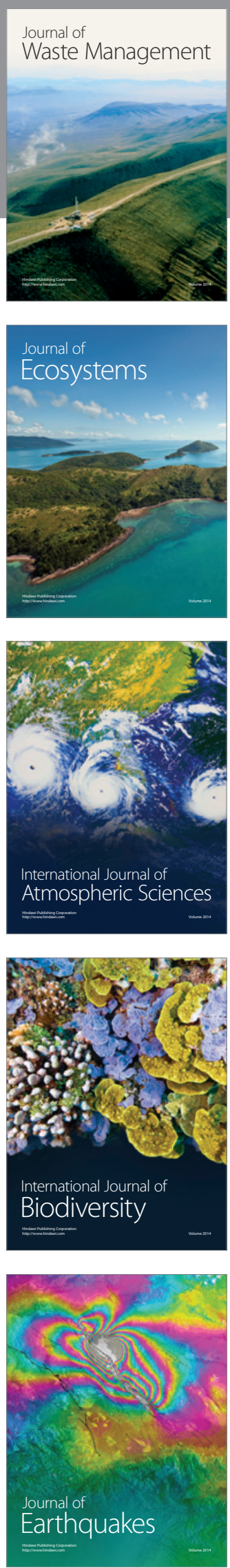
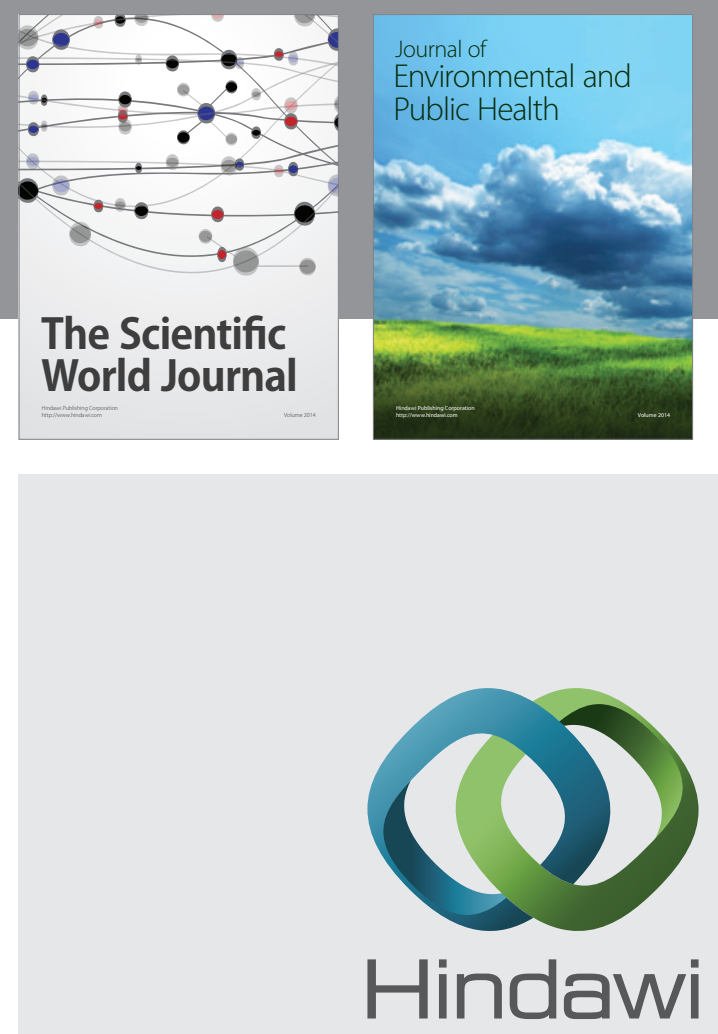

Submit your manuscripts at

http://www.hindawi.com
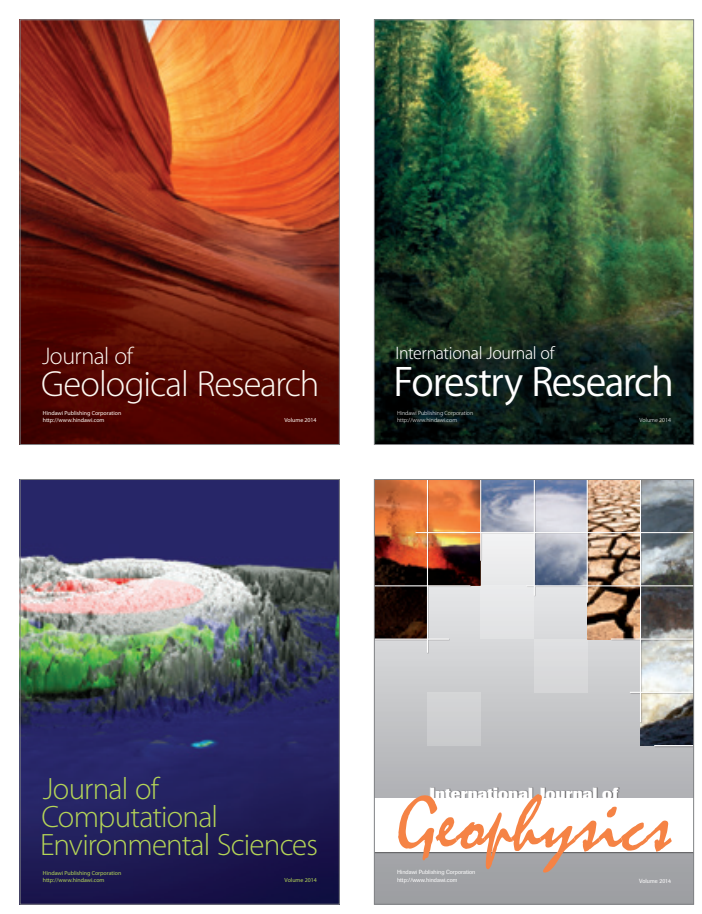
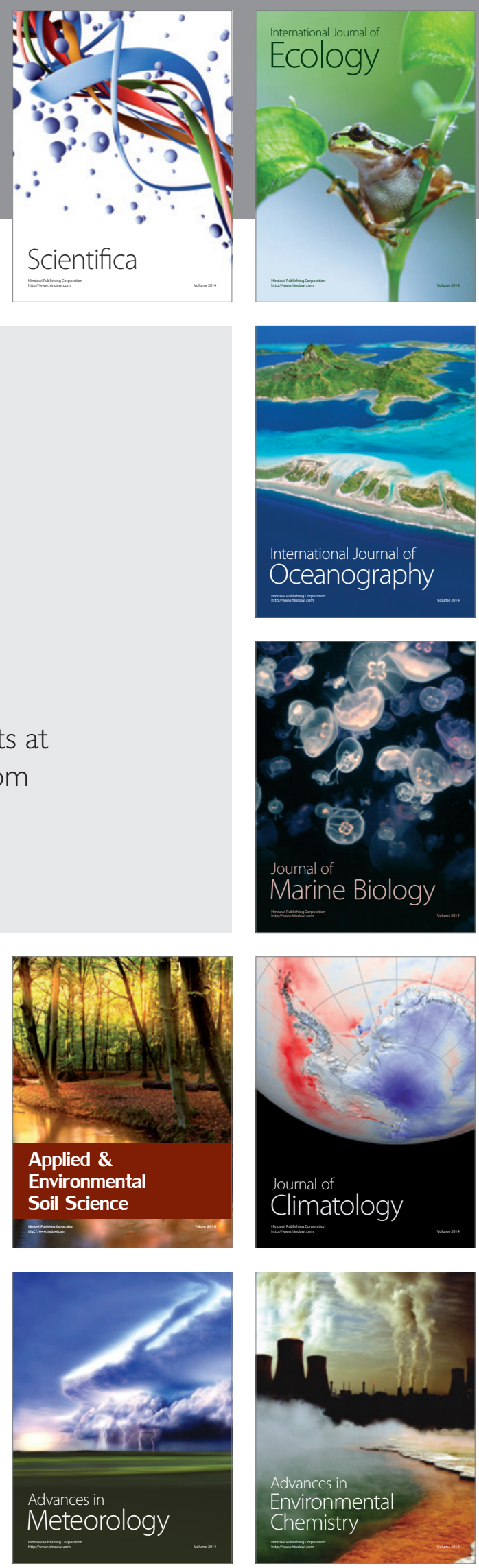